\title{
ORGANISATION OF A SPINAL INJURIES UNIT WITHIN A UNIVERSITY HOSPITAL
}

\author{
By Docent Volkmar Paeslack, M.D. \\ Orthopaedic University Hospital, Heidelberg, Germany \\ Spinal Injuries Centre
}

UNTIL today, the demands and principles of rehabilitation have received only insufficient consideration in clinical medicine. Traditionally, the physician sees his duty in the curing and improving of pathological conditions or symptomsand thus Imhotep's principles as laid down in the Smith papyrus 5000 years ago are still valid today: According to these, diseases are categorised in those which the physician can cure, in those where treatment is possible but therapeutic success is doubtful, and in those which cannot be treated at all.

Paraplegia belongs to those conditions which physicians in Ancient Egypt considered incurable and which therefore remained untreated. Even today, permanent disabilities and irreversible states of impediment are often considered to be less interesting from the therapeutic point of view. To provide care for these cases is the duty of charity organisations or public and private social assistance services-the doctor feels only seldom or not at all challenged.

This fact becomes even more evident in the curricula of German medical schools. Until today, problems of rehabilitation are rarely subjects of research and teaching. The medical student, the future doctor, is only insufficiently or not at all confronted with problems of habilitation or rehabilitation of physically or mentally disabled people. The impact of the many changes of social, political and economic patterns which have taken place in recent decades, and resulting from this the many changes in the conception of man and his environment, will be felt only gradually and not immediately in the deep-rooted traditional university system. But in spite of that it sometimes happens that medical traditions, observed many thousand years and still transmitted through our medical schools, are questioned and considerably shaken. The inclusion of social aspects in all fields of medical activities - and perhaps one of the most important aspects is rehabilitation-will be one of the decisive revolutionary events in medicine in our time. Our medical schools only give insufficient consideration to this fact. Therefore, rehabilitation as far as its basic socio-medical ideas are concerned have been developed mainly outside clinical medicine; thus medical students today have rarely the opportunity of becoming familiar with methods and facilities of rehabilitation within the framework of their studies.

Therefore, it seems the more important that, in recent years, some centres for a comprehensive service for spinal paraplegics have been established and attached to various European universities. Naturally, comprehensive treatment facilities for paraplegics and tetraplegics are still insufficient and there is a need to increase the number of Spinal Injuries Centres.

As far as I know, there are six units for paraplegics in the whole of Europe, which are attached to the universities: Brussels, Warsaw, Geneva, Heidelberg, Cologne and Basle. As to their structure and organisation, these units differ in size and in the ways they are attached to general or specialised hospitals, or they are even completely independent. Therefore, the rehabilitation centre for 
paraplegics in Heidelberg which we are going to describe is only one possibility, in which patients with spinal injuries can be treated in the acute and later stages after injury.

About ten years ago there was already a small special ward for paraplegics with 25 beds, which was part of the Orthopaedic Clinic of the University of Heidelberg as a result of Guttmann's concept and experience that a paraplegic cannot be adequately treated in a general ward, and that it is necessary to establish a special unit for this group of patients. Based on that concept, the late director of the Orthopaedic University Clinic of Heidelberg, Professor Kurt Lindemann, planned to establish a larger unit for paraplegics which was to be attached to the Orthopaedic Clinic. In the course of planning, the urgent question arose as to what was to be done with the many young paraplegics after successfully completed medical treatment. Therefore, we extended our project and established a centre with two departments which are almost equal in size: an in-patient clinical unit with approximately 60 beds, called Ludwig Guttmann-Haus, and second unit for vocational and social rehabilitation with a boarding-school and training workshops where 60 patients can be vocationally trained. This unit was named in memory of its creator, the Kurt Lindemann-Haus. The Orthopaedic University Clinic, with about 500 beds, the largest of all clinics of the University of Heidelberg, is a private foundation. It is situated on the outskirts of Heidelberg, upstream the River Neckar, in the most picturesque surroundings. The centre for paraplegics lies within the clinic grounds and represents a special department of the hospital With regard to its size, equipment and scope of tasks it is independent to a certain degree, and in accordance with the wish of the authorities concerned this degree of independence will become even more apparent in the future.

The clinical unit for the treatment of acute spinal injuries and for spinal patients suffering from other causes has two wards for men and one for women, and in addition a children's ward which is near its construction; it includes a large department for physiotherapy, sports facilities, a hydrotherapy department and a department for occupational therapy. Special rooms for X-ray, urological treatment and an out-patient unit are part of the clinical department. If surgical treatment is necessary, this is performed in the Surgical Unit of the Orthopaedic Clinic. In the Department for Vocational Training men and women with spinal lesions-and among them an ever-increasing number of tetraplegics-are trained as business-men, technical designers, mechanics, or in the manufacturing of precision tools. We usually accommodate two patients in one room. Training takes between one and a half to two vears. At the end of this period the trainees have to take an examen before a professional authority. Besides professional training this unit is also concerned with job finding and work-load testing.

The centre was financed by the endowment funds of the Orthopaedic Clinic and with the assistance of public authorities. It was established as a model centre in which, on the one hand, research is carried out in the field of spinal injuries where new methods of treatment and management are tried out and, on the other hand, new principles of comprehensive rehabilitation are elaborated. Moreover, architectural, organisational and structural problems related to the equipment of rehabilitation centres are investigated. Theoretical as well as practical training of medical students is undertaken within the framework of general lectures on orthopaedic subjects but also within the framework of special 
lectures on specific problems in spinal lesions and rehabilitation. In the course of this programme we also train physiotherapists, occupational therapists and, above all, nursing staff. Refresher courses may take one to three days, while more comprehensive training courses take three to four months. Candidates for a doctor's degree are working in smaller groups when investigating special problems of paraplegia. Through scientific congresses and by advanced training courses for physicians and surgeons we are trying to collect and widen our experiences in this particular subject of medicine.

We seek, as other specialists do, close co-operation with other branches of medicine which are involved in the treatment of paraplegics and tetraplegics. In order to achieve such a close relationship we are going to organise interdisciplinary lectures to stimulate the exchange of experiences with other branches of medicine.

Another field of importance to which we give much attention is documentation and collecting of material dealing with rehabilitation as a special medical problem. In this respect we have established contact with other paraplegic units to pool experience on both medical and social problems.

One day when discussing rehabilitation problems with a well-known professor and director of a large university hospital, he expressed concern that a rehabilitation centre for paraplegics of the size of the Heidelberg centre might, like a hydrocephalus, disturb the organisational equilibrium of a hospital. While I can understand his concern, I cannot accept this view at all. I believe that a rehabilitation centre of this size may certainly become an important section of a large hospital and it may even become an integral part of the whole medical faculty of a university and may, by its initiative and work, exert a beneficial influence on other sections of the hospital and medical faculty as a whole. While such a specialised centre needs the co-operation and facilities of other specialities, its own facilities and the specialised knowledge of its staff can be of considerable benefit to other departments and thus make its contribution to the work of the hospital and medical faculty as a whole.

Let me conclude with a statement Lindemann made in I965: 'If we want to further and promote the concept and ideas of rehabilitation, and if we want to develop all measures serving the cause of rehabilitation, then science will have to deal with rehabilitation, and thus rehabilitation will become a subject of university research and teaching.'

\title{
THE MIDLAND SPINAL INJURY UNIT AT THE ROBERT JONES AND AGNES HUNT ORTHOPAEDIC HOSPITAL, OSWESTRY
}

\author{
By Terence McSweeney, M.Ch.(N.U.I.), M.Ch.(Orth.), F.R.C.S.(Eng.) \\ South Cheshire Hospital and the Robert Fones and Agnes Hunt \\ Orthopaedic Hospital, Oswestry
}

Assuming that our Continental colleagues may not be familiar with the Robert Jones and Agnes Hunt Orthopaedic Hospital, I thought I should begin with a brief historical account of the hospital. 